\title{
Apresentação do dossiê: Nova História Militar
}

\section{Presentation of the dossier: New Military History} José Miguel Arias Neto 
A designação “História Militar”, como quase tudo em História, está sujeita a discordâncias, controvérsias e disputas. De fato, como gênero historiográfico, a História Militar surge no final dos Oitocentos, derivada das histórias nacionais, isto é, emerge como narrativa das guerras que deram origem e formação dos Estados Nacionais naquele período.

Como consequência, as doutrinas sobre a Guerra, a do militar prussiano Carl von Clausewitz e, especialmente a de Jomini, marcaram a compreensão da História Militar de uma perspectiva ciceroniana, isto é, uma espécie de "mestra da vida". Tratava-se de compreender os "acertos”, mas principalmente os "erros" militares para corrigi-los tendo em vista a realização da guerra, conceituada como “continuidade da política por outros meios”, fórmula célebre em determinados meios civis e militares.

Neste sentido, a História Militar tinha um aspecto didático muito claro: ela propiciaria exemplos para a formação das novas gerações de militares. Exemplos de guerras bem ou mal sucedidas, mas também, de guerreiros heróis (modelos morais) que serviriam para inspirar as novas gerações de soldados. Assim, este tipo de história militar, configura uma espécie de repositório moral que se coloca no plano da memorialística, da mitificação, fruto de uma reconstrução do passado com finalidade doutrinária.

Se assim fosse, porém, os historiadores contemporâneos pouco teriam a dizer sobre fenômenos militares. Mas felizmente não é o caso. A História Militar stricto sensu, isto é, enquanto campo historiográfico, emerge da ruptura da historiografia com a história nacionalista colocando em foco os homens, suas ações, dilemas e tragédias, com base em investigação temática e documental diversa e multifacetada. Assim não só aquela velha “história militar" se torna fonte e objeto de investigação, como também novos temas como as instituições militares, seu funcionamento e idiossincrasias, a vida dos soldados, o quotidiano das guerras, os estudos de gênero, focalizando a presença de mulheres e gays no âmbito das Forças Armadas, bem como a desconstrução das batalhas, dentre outras inúmeras problemáticas.

No caso do Brasil, a história militar tem especial interesse. Não porque o país tenha participado de extensas guerras. Ao contrário, stricto sensu podese dizer que a guerra da Tríplice Aliança contra o Paraguai foi, de fato, o único conflito externo travado pelo Brasil e com participações limitadas, mas de grande impacto interno, na I e na II Guerras Mundiais. O que também torna o estudo das questões militares no Brasil relevante reside na longa tradição de participação dos militares na política nacional. 
Embora alguns analistas datem o início destas intervenções com o golpe militar que instituiu a República, este evento foi a manifestação pública de um processo que se desenvolvia, pelo menos desde meados do século XIX, acelerado pela crise provocada pelo conflito no Prata.

Recentemente, no período da assim chamada redemocratização brasileira, houve um renovado interesse nas discussões acerca da defesa nacional, e neste contexto, por iniciativa civil, foi criada a ABED- Associação Brasileira de Estudos de Defesa, que tem por objetivo o estudo de questões de defesa.

Por outro lado, além dos estudos de defesa, na ABED, formou-se também um grupo vinculado ao estudo da História Militar. Este grupo cresceu e adquiriu autonomia e dimensão suficientes para criar um Simpósio Nacional de História Militar em 2016, um Grupo de Trabalho de História Militar no âmbito da ANPUH- Associação Nacional de História em 2019 e, finalmente, desde o IV SNHM realizado na Universidade Estadual de Londrina, também em 2019, buscar a criação de uma Associação Brasileira de História Militar.

O que importa ao grupo de pesquisadores da História Militar é a colaboração acadêmica na área de História, da iniciação científica à pósgraduação. Isto tem promovido a aproximação dos historiadores que se dedicam à pesquisa dos fenômenos militares.

Finalmente, cabe destacar que o presente dossiê é parte das contribuições que a Universidade Estadual de Londrina e o Programa de Pós-Graduação em História Social têm dado continuamente à área. Em 2009, a UEL sediou o III Encontro da ABED. Naquele mesmo ano, foi publicado um dossiê sobre História e Defesa nesta revista. Em 2010, foi publicado um dossiê sobre os Cem Anos da Revolta da Chibata e, em 2014, um tematizando a Cultura Marítima. Além disto, em 2019 o Grupo de Pesquisa em Estudos Culturais Política e Mídia, o GT de História Militar da ANPUH do Paraná, o Departamento de História e o Programa de Pós Graduação em História Social organizaram, com a colaboração dos GTS de História Militar do Rio de Janeiro e do Rio Grande do Sul, o IV Simpósio Nacional de História Militar. Paralelamente, organizou-se o presente dossiê sobre a Nova História Militar.

Foi uma honra ter contato com a colaboração, na organização deste, dos professores António Manuel Fernandes da Silva Ribeiro do Instituto Superior de Ciências Sociais e Políticas -Universidade de Lisboa e Francisco Eduardo Alves de Almeida da Escola de Guerra Naval, cuja presença aponta para uma ampliação da colaboração internacional no campo e com o Programa de Pós- 
Graduação em História Social da Universidade Estadual de Londrina.

Não foi surpresa, assim, o grande número de artigos enviados para a Revista, num total de vinte e quatro. Difícil a tarefa de selecionar os onze textos aqui publicados e que constituem uma amostragem da excelência do campo.

Abrindo o dossiê, no texto "Na perda da opinião, arrisca-se um reino”, Marcello Loureiro analisa as condições da guerra nos séculos XVI e XVII, para compreender as tentativas de formação das opiniões durante os conflitos. Faz um balanço da historiografia acerca da questão da opinião coletiva na modernidade, seguido dos estudos de caso da monarquia portuguesa em torno da entrega de Pernambuco em 1648, mas elenca também exemplos da península itálica e da França, para concluir que é preciso superar a lógica de uma doutrina militar - especialmente a clausewitiziana - para se compreender os conflitos da modernidade.

Na sequência, Ana Paula Wagner e Bruno César Pereira no artigo intitulado "Que sendo de uma indispensável necessidade para a confecção do exército, em que consiste a manutenção e a defesa dos meus reinos: Notas sobre a nova forma de se fazer recrutas no Império Português (Século XVIII)”, analisam a reforma das formas de recrutamento paras as Tropas Regulares do Império Português, destacando as preocupações em delimitar o perfil dos homens a serem recrutados e as estratégias utilizadas por estes para eximir-se de sentar-praça.

Já Christiane Figueiredo Pagano de Mello, em seu texto “Política Militar Pombalina: nas áreas de alto e baixo risco de guerra” desvenda a estratégia 'Defender para povoar' da administração pombalina analisando os efeitos das reformas militares do período na região do Macapá, considerada como território de alto risco. Faz para isto, uma comparação com as regiões norte e centro-sul da América para compreender de modo mais amplo a política militar portuguesa nas suas colônias ultramarinas.

Por sua vez, Sérgio Willian de Castro Oliveira Filho, no texto “Em prol da moralidade e da disciplina: os oficiais do culto da Marinha imperial ente 1822 e 1865", analisa - no contexto da institucionalização da Marinha - que pouco se fez para a efetivação de um Corpo Eclesiástico profissionalizado. Assim, recupera a atuação dos oficiais de culto da armada imperial e os discursos da imprensa e dos relatórios de ministros sobre estes oficiais e suas atribuições.

Em instigante artigo intitulado “Corrupção na armada imperial: fraudes no provimento de carvão para os navios de guerra da Marinha ( 1877-1879)", Pablo Nunes Pereira e William Gaia Farias discutem o tema pouco explorado dos 
processos de corrupção no abastecimento do carvão para os navios de guerra situando-o em um contexto de transformações em máquinas de navegação, embarcações durante o desenvolvimento do capitalismo industrial da segunda metade do século XIX.

Ludolf Waldmann Júnior, analisa em seu artigo os Programas Navais da Argentina durante a Segunda Guerra Mundial, demonstrando que, inicialmente, os planos de renovação da esquadra foram feitos tendo em vista retomada da hegemonia argentina na América do Sul, numa complexa teia de relações que articulavam questões externas e internas. Ao longo da guerra, no entanto, e devido às mudanças tecnológicas na construção naval e nos armamentos, estes planos foram se modificando.

Entre 1937 a 1947, Apolônio de Carvalho filiou-se ao Partido Comunista do Brasil, lutou na guerra civil espanhola ao lado dos republicanos e engajouse na resistência francesa ao nazismo. A trajetória antifascista, bem como as memórias que produziu sobre esta militância é estudada por Marco Antonio Machado Lima Pereira, em envolvente artigo sobre este oficial do Exército, que lutou também na resistência à ditadura militar no Brasil e foi militante do Partido dos Trabalhadores desde sua fundação.

Rosemeri Moreira aborda em seu texto "Heroínas, gênero e guerras" as representações do feminino e das heroínas de guerra presentes na imprensa militar dos anos de 1942 a 1945. São analisadas diferentes publicações sobre as mulheres nas revistas militares: A Defesa Nacional; Nação Armada e Revista Militar Brasileira.

Em texto instigante, Francisco Cesar Alves Ferraz demonstra que o fato da composição racial da Força Expedicionária Brasileira - FEB, espelhar a estrutura multiétnica da sociedade brasileira, foi um resultado não planejado pelas autoridades do Exército. Estas desejavam uma composição de "elite" em termos físicos e de alfabetização, mas enfrentaram dificuldades - resistência mesmo - no recrutamento de membros das classes mais elevadas e da classe média brasileira predominantemente "brancas", o que resultou em uma tropa mais diversa do ponto de vista racial.

Claudio Beserra de Vasconcelos em seu artigo sobre a Escola Superior de Guerra (ESG), analisa as políticas repressivas aplicadas a militares após o golpe de 1964, baseadas nas doutrinas de segurança nacional e de guerra revolucionária. Desvenda assim não apenas as fundamentações ideológicas e políticas, mas também os métodos e focos deste processo.

Finalmente, Francisco Eduardo Alves de Almeida, demonstra no seu 
artigo, o ainda pequeno número de trabalhos sobre História Naval nos meios acadêmicos, a partir de levantamento do catálogo de teses e dissertações da CAPES entre os anos de 2016 e 2018. Serve como estímulo aos pesquisadores a se debruçarem sobre a temática em seus trabalhos já que se trata de campo fértil e inexplorado pelos historiadores.

Há indícios notáveis de que os estudos de História Militar no Brasil têm enorme potencialidade e muito trabalho a fazer. Como se sabe, o futuro é imprevisível, mas por esta amostragem podemos ao menos divisar que o papel da História no processo de construção de conhecimento sobre os fenômenos militares, do passado e do presente, é fundamental para a democratização da sociedade brasileira.

\section{Notas}

${ }^{1}$ Universidade Estadual de Londrina. 